tion is good. None of my patients has had disturbances of the nerve afterward, perhaps because I did not go far enough to remove the entire process. There certainly is a group of cases which should be operated on, but I believe tise majority of cases, as in cervical ribs, give no symptoms, and probahly should be let aloze.

Dr. E. W. Ryerson, Chicago: I have operated on only one of these patients, a woman from South Carolina, who had a very large bifid process. She had undergone two laparotomies on the left side and nothing was found, : that it was pretty evident she had a great deal of pain from this condition. I found the operation unusually difficult, but it was easy to get down to the process by making an incision well to the outer side of the crector spinae muscles. If one goes through the muscles not sufficient room can be gained, and it is not perhaps well to cut through such a large body of muscle; but going just to the outer side of the muscle the access is very easy to the outer part of this transverse process, although it is extremely difficult to get it out. In this operation I only got out the upper half of this biffd process. Nevertheless this patient was much relieved. She had paresthesia for three or four days afterward, but this entirely disappeared. Apparently she is at present free from symptoms. The difficult thing to understand is why removing the top of a bifid process which was not articulating with the ilium should do any good, but the fact is that it has relieved this patient. We do not know all about the nerve disturbances and nerve supplies, hecause, as Dr. Fassett said, the supply for the anterior ibial nerve comes from higher up; but the paresthesia my patient complained of was distinctly over the anterior tibial region. I cannot sec how these patients can get more relief than by submitting to an operation, because they will not consent to wear through life a long plaster jacket or other apparatus.

Dr. Wallace Blanchard, Chicago: I reported at the last meeting of the American Orthopedic Association removal of the transverse process of the fifth lumbar vertebra that impinged on the wing of the ilium. It showed an elongation ahout twice the normal, as compared with the transverse process of the other side. A perpendicular incision of about 5 inches through the erector spinae muscles and direct down to the transverse process, removing by chisel and forceps, was not an overdifficult operation. The transverse process could be easily reached and removed. After resection the Roentgen ray showed a stump and a space between the stump and the wing of the ilium. There were no bad symptoms following the operation - of anesthesia, hyperthesia, etc., that have been told of by Dr. Fassett, and the patient made a good recovery. The patient had been paralyzed from the shoulder down through the left side to the left leg, and had had two abdominal operations, and the appendix had been removed, all in the hope of relieving painful conditions that were undoubtedly caused by the impingement of the transverse process and the ilium. The cure was immediate and there were no bad symptoms following the operation.

Dr. Roland Meisenbach, Buffalo: In connection with the operation for the removal of the transverse process of the fifth lumbar vertebra, a point that should be emphasized is that great care must be taken so as not unduly to divide nerve structures in the region of the lumbar plexus. I think that operation of these cases should only be undertaken in the severe type, and all other means should first be attempted to relieve the symptoms. There is one case that is of interest, which is rather unique, and which was sent to me for relief. It was a man of good musculature who had been employed at heavy work. At the time of the accident he was holding a rope taut. The rope suddenly parted and he was thrown backward to the ground. He complained of severe pain in the lower part of his back and was taken to the hospital. At the time I saw him, a few months after the accident, he complained of severe pain whenever he turned around in bed or attempted to walk, or on any lateral motion of the body. The radiograph showed that the transverse process of the fifth lumbar vertebra had been obliquely fractured and the fragments separated and displaced, so thit the outer portion was drawn downward. A large callus had formed. This callus expanded and amalgamated with the ilium and the sacrum. To give the man relief it was necessary for me to remove the process, which was done. I think in general that a small incision should be made. By a small incision I mean after the first layer of muscles has been divided, and I also think it is much better to divide the muscle fibers with blunt dissectors until one reaches the transverse process. This minimizes the hemorrlage and facilitates the removal of the process. If the periosteal dissector or a chisel is used to peel the periosteum of the process, the chain saw may be brought around and the process removed. I think the use of a chain saw is much better than the use of a chisel, because with the chisel the process is brought out in a piecemeal fashion and there is more danger of injuring the structures. I wish also to emphasize the fact that just anterior to the process one is apt to meet nerve structures and ganglia that should not be touched with the instrument. In one instance I remember that the patient suddenly stopped breathing when these were touched, and I only mention it as a point of interest which should be kept in mind in removing the transverse process of the fifth lumbar vertebra.

Dr. J. P. LoRd, Omaha: I wish to report the development of pain on the second day of a recent case. The pain. became progressively worse after twenty-four hours. Coming on so late, it occurred to me that it was induced by hemorrhages and infiltration. This might readily be imagined to take place because of the loose tissues in this region, the exudate enveloping these nerve trunks. There was muscle paralysis also, and this lasted for four or five days, when rapid improvement ensued. I would suggest this as a possible explanation of the pain.

Dr. Fred. J. FAssetr, Seattle: There is only one thing to add, and that is on the matter of a choice between a chisel and the wire saw. With me it was not a matter of choice at all. I started in equipped with very little except my knife and wire saw, it looked so easy in the roentgenogram. But in none of these cases did I use the wire saw, except when I removed the fourth process. When it comes to the fifth, the passing of the wire saw around the neck of the process required more nerve than even I have developed.

\section{ANALYSIS - OF FOUR HUNDRED CASES OF LOBAR PNEUMONIA *}

\section{J. G. CROSS, M.S., M.D. MIN NEAPOLIS}

There were 83,778 deaths from pneumonia in the Inited States registration area in the year 1913, or 132.4 deaths from this disease per hundred thousand population. In Minneapolis there were 348 deaths from the same cause, or 104 per hundred thousand population. For comparison, in the same year 80,812 persons died from pulmonary tuberculosis in the United States registration area, or 127.7 per hundred thousand population. In Minneapolis there were 383 deaths from pulmonary tuberculosis, or 118 per hundred thousand population. In 1914 there was an increase in the death rate from pneumonia and a decrease in the death rate from pulmonary tuberculosis.

These figures are presented to fix our attention again on the importance of pneumonia. With cancer and pulmonary tuberculosis it forms a dread trio. The death rate from pneumonia has not decreased. In some localities statistical observation shows that not only is pneumonia on the increase but in certain out-

* Read before the Minnesota State Medical Association, Rochester, Oct. 1, 1915. 
breaks it is actually more fatal than it was in former periods of time. From the figures given above it would seem that less advance has been made in the prevention and treatment of pneumonia than in prevention and treatment of tuberculosis.

In an attempt to study certain features of pneumonia, data in a large number of cases of lobar and bronchopneumonia at the Minneapolis City Hospital for the years 1911, 1912, 1913 and 1914 have been collected and analyzed under the headings of age, sex, occupation, date of onset, character of onset and initial symptoms, later symptoms, the maximum temperature, laboratory findings, physical findings, the white blood count, the complications, the termination, whether by death, lysis or crisis, and necropsy findings, if a postmortem examination was made. This analysis has borne out many conclusions which are not new, and has verified some impressions which needed the corroboration of actual statistics. In the present paper I intend to present an abstract of the results of this analysis as regards lobar pneumonia alone.

As will appear in a later statement as to the time in the disease at which patients are admitted, it is evident that the mortality of lobar pneumonia at the City Hospital is much higher than it would be under vidual resistance plays a very great part in the number of cases in the presence of infection. The influence of season is, of course, apparent.

There were 369 cases of lobar pneumonia at the City Hospital in the four years 1911, 1912, 1913 and 1914. Of these, 117 patients died-a mortality of 31 per cent. Chart 1 illustrates the death rate at the ages from 1 to 5,5 to 10 and then by decades. It was found necessary in analyzing the cases of children to separate those under 5 and over 5 , the mortality was so strikingly different in the two five-year jeriods. As will be seen, the mortality in the succeeding decades rises steadily and consistently.

In Chart 2 is shown the termination of the cases in which the patients recovered by lysis or crisis, according to the same age periods.

As to the day on which crisis took place, we find a surprising condition of things in this series of cases. There were 125 cases in which the exact date of onset of the disease and the time of crisis could be determined. It is found that there is no regularity in the time at which the crisis occurred. Table 2 illustrates this fact. It will be seen that while in 80 per cent. of the cases the crisis occurred before the tenth day, in seven cases it fell on the tenth; in nine, on the twelfth; in six, from the seventeenth to the twenty-

TABLE 1.-MORTALITY STATISTICS

\begin{tabular}{|c|c|c|c|c|c|c|}
\hline \multirow{3}{*}{ Causes of Death } & \multirow{2}{*}{\multicolumn{2}{|c|}{$\begin{array}{l}\text { U. S. Registration } \\
\text { Area, } 1913\end{array}$}} & \multicolumn{4}{|c|}{ City of Minneapolis } \\
\hline & & & \multicolumn{2}{|c|}{1913} & \multicolumn{2}{|c|}{1914} \\
\hline & Number & Per 100,000 & Number & Per 100,000 & Number & Per 100,000 \\
\hline 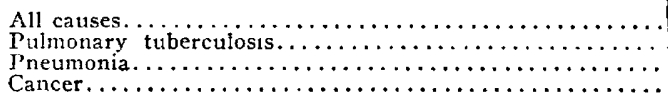 & $\begin{array}{r}890,848 \\
80,812 \\
83,778 \\
49,928\end{array}$ & $\begin{aligned} i 27.7 \\
132.4 \\
78.9\end{aligned}$ & $\begin{array}{r}3,862 \\
383 \\
348 \\
276\end{array}$ & $\begin{array}{l}113 . \\
104.3 \\
81.9\end{array}$ & $\begin{array}{r}4,115 \\
385 \\
433 \\
311\end{array}$ & $\begin{array}{l}112.09 \\
126.06 \\
90.5\end{array}$ \\
\hline
\end{tabular}

average conditions in private practice. Several factors contribute to this. First of all, the City Hospital admits that large class of homeless or destitute patients who are careless of the onset of an acute disease. It is the rule that these people neglect the first few days of an acute illness until compelled to seek help through inability to care for themselves. Many patients are weakened by bad hygiene or vicious - habits, together with irregular, too little or improper food. Many are chronic alcoholics. Acute alcoholism also plays a larger rôle than would be the case in the same number of private patients. Another factor in the free hospital treatment of pneumonia, as in other diseases, is the frequent lack of intelligent cooperation on the part of the patient. Ignorance of disease and fear undoubtedly have a great deal to do with the outcome.

Another striking fact brought out is that not only do the number of cases vary in different seasons and the same season of different years, but the mortality is much greater sometimes than at others. This difference in mortality has not been satisfactorily explained and is probably due to the combination of a number of causes rather than to any one variable factor. There is undoubtedly a difference in the virulence of the pneumococcus infection, but this alone does not explain the variations in mortality or the incidence of the disease. The undoubted fact that many people harbor the pneumococcus in their respiratory tracts, without becoming ill, shows that indi- first day, and in two was delayed until one month after the onset.

In 264 cases the initial symptom was definitely known (Table 3 ). In 121 , or 46 per cent., a chill

TABLE 2.-DAY OF CRISIS AFTER ONSET IN 125 CASES OF LOBAR PNEUMONIA
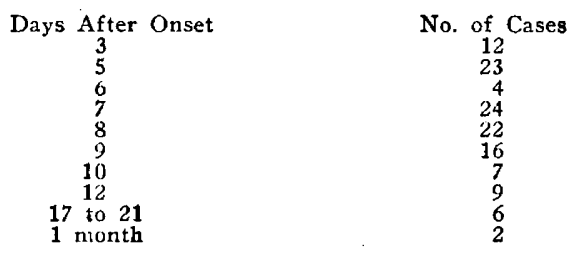

TABLE 3.-INITIAL SYMPTOM IN 264 CASES OF LOBAR PNEUMONIA

\begin{tabular}{|c|c|c|}
\hline Symptom & No. & Per Cent. \\
\hline 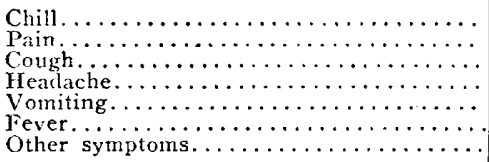 & $\begin{array}{r}121 \\
38 \\
33 \\
21 \\
12 \\
12 \\
27\end{array}$ & $\begin{array}{r}46 \\
14 \\
12 \\
7 \\
4 \\
4 \\
10\end{array}$ \\
\hline
\end{tabular}

ushered in the disease; next most common was pain in the side, back or chest; thirty-eight cases, or 14 per cent., had this first; in thirty-three, or 12 per cent., a cough was the first thing evident; in twenty-one, or 
7 per cent., it was headache; in twelve, or 4 per cent., vomiting was first noticed; in twelve, or 4 per cent., fever only, and other symptoms of various nature in 1 wenty-seven cases, or 10 per cent. These symptoms naturally occurred in combination or one rapidly following the other, but it is intended to note in this connection only that which first called the attention of the patient to his abnormal condition.

Examination of the urine ( $\mathrm{Ta}$ ble 4) shows the presence of abnormality in 237 of the 369 cases. This does not mean, however, that the remaining patients did not have abnormal urine findings. Many of our patients came in moribund, and for that or some other reason the urine could not be obtained in every case. In the 237 cases, however, sixty-one, or 25 per cent., showed the presence of albumin; twentyseven, or 11 per cent., showed casts in the urine, and in 149 cases, or 63 per cent., both albumin and casts were present.

It is interesting to note the lo-
These figures agree in the main with those of Preble's 9,333 cases collected in 1904.

It is found in the foregoing that in 67 per cent. of the cases the leukocyte count ranged between ten and twenty-five thousand, as given in Table 6 .

Leukocytosis in lobar pneumonia deserves consideration. In this collection of cases an attempt was made to discover the relation, if any exists, between the number of white blood cells and the course of the disease. For this purpose, cases with complications, especially suppurative conditions, were excluded. Children under 14 years of age were also excluded. Those remaining were classified according to the number of leukocytes found, without regard to age, amount of consolidation, or other conditions. As will be seen from Table 7, the six groups have been made according to the number of leukocytes and the percentage taken of cases in each group, which ended in lysis, crisis or death.

A study of Table 7 presents
TABLE 4.-EXAMINATION OF URINE IN 237 CASES OF LOBAR PNEUMONIA

\begin{tabular}{|c|c|c|}
\hline Findings & No. & Per Cent. \\
\hline $\begin{array}{l}\text { Albumin present only } \ldots \ldots \ldots \ldots \ldots \ldots \ldots \ldots \\
\text { Casts only } \ldots \ldots \ldots \ldots \ldots \ldots \ldots \\
\text { Both albumin and casts } \ldots \ldots \ldots \ldots \ldots \ldots\end{array}$ & $\begin{array}{r}61 \\
27 \\
149\end{array}$ & $\begin{array}{l}25 \\
11 \\
63\end{array}$ \\
\hline
\end{tabular}

some interesting features. The selection of uncomplicated cases does not, of course, give the same percentage of deaths or termination of lysis or crisis, as does the whole series of cases, including complications and all ages. It is seen at once that a leukocytosis under 10,000 gives $33 \frac{1}{3}$ per cent. of deaths, which is in accordance with our general knowledge that a low resistance with low leukocyte reaction gives an unfavorable prognosis. We find again that a white count between ten and fifteen thousand or between twenty and twenty-five thousand gives us

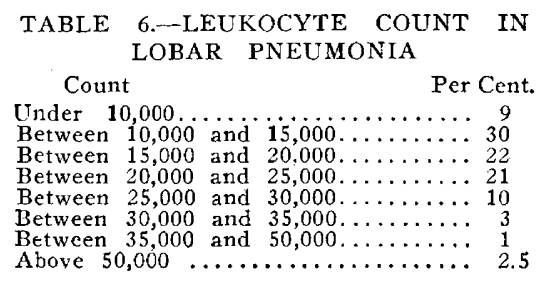
LOBAR PNEUMONIA Count Per Cent. Under $10,000 \ldots \ldots \ldots \ldots \ldots \ldots \ldots \ldots$ Between 10,000 and $15,000 \ldots \ldots \ldots \ldots, 30$ Between 20,000 and $25,000 \ldots \ldots \ldots \ldots \ldots 21$ Between 25,000 and $30,000 \ldots \ldots \ldots \ldots 10$

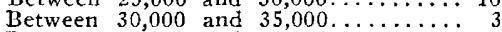
Between 35,000 and $50,000 \ldots \ldots \ldots \ldots, 1$

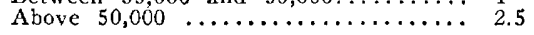

nearly the normal rate of mortality, namely, 22 and 24 per cent. Between fifteen and twenty thonsand leukocytes strangely seems to give a lower mortality, for which no explanation is offered and
Chart 2.-Termination in 369 cases of lobar pneumonia by lysis and crisis; solid line, crisi
cases; broken line, lysis cases. which may mean nothing. With the higher white counts above 25,000 , the mortality is lower by one half, being only 11.3 per cent.

It may be concluded then, as far as mortality from lobar pneumonia is concerned, that the higher the white blood count the better the prognosis, and that a count of 25,000 or over is decidedly more favorable than under 25,000 .

We next notice that the proportion of the cases terminating in lysis and crisis is rather uniform untii the white count reaches 20,000 or over. Between twenty and twenty-five thousand an equal number of 
cases ended in each way. Between twenty-five and thirty thousand there is a decided preponderance of cases ending in lysis in the proportion of $1: 2$. When the white count is over 30,000 , however, this proportion is almost exactly reversed, there being $331 / 3$ per cent. ending in lysis and 55.4 per cent. in crisis.

As has been stated, many of the patients in this series were admitted at a relatively late date in the course of the illness. These might roughly be divided into two classes. In the first division are those patients who were admitted in the first acute stages and in another class those in whose cases recovery was delayed beyond the first two weeks and who were brought in later either for delayed resolution o: some complication. Without, however, thus classifying them, we find that it is very rare for a patient with lobar pneumonia to be admitted before the third day after the onset, and that 70 per cent. of them are admitted on the third, fourth, fifth, sixth and seventh day in about equal numbers. The bearing of this fact in our mortality records is obvious.

An analysis of cases of bronchopneumonia was made at the same time as the lobar cases. As bronchopneumonia, however, presents such a different aspect and much more varied etiology and course, this abstract does not cover that class of cases.

TABLE 7.-RELATION OF LEUKOCYTOSIS TO THE COURSE OF LOBAR PNEUMONIA IN 184 CASES

\begin{tabular}{|c|c|c|c|c|}
\hline No. & $\begin{array}{c}\text { Leukocytes } \\
\text { Per Cent. }\end{array}$ & $\begin{array}{c}\text { Lysis } \\
\text { Per Cent. }\end{array}$ & $\begin{array}{c}\text { Crisis } \\
\text { Per Cent. }\end{array}$ & $\begin{array}{c}\text { Deaths } \\
\text { Per Cent. }\end{array}$ \\
\hline $\begin{array}{l}\text { From } 5,000 \text { to } 10,000 \ldots \\
\text { From } 10,000 \text { to } 15,000 \ldots \\
\text { From } 15,000 \text { to } 20,000 \ldots \\
\text { From } 20,000 \text { to } 25,000 \ldots \\
\text { Jrom } 25,000 \text { to } 30,000 \ldots \\
30,000 \text { and over. } \\
\text { Totals } \ldots \ldots \ldots \ldots \\
\text { Tota. . . }\end{array}$ & $\begin{array}{l}9.8 \\
27 \\
26 \\
19.6 \\
7.6 \\
9 \\
\cdots\end{array}$ & $\begin{array}{l}38.8 \\
44 \\
41.6 \\
38.8 \\
57.1 \\
33.3 \\
41.6\end{array}$ & $\begin{array}{l}27.7 \\
32 \\
39.1 \\
38.8 \\
28.5 \\
55.4 \\
36.9\end{array}$ & $\begin{array}{l}33.3 \\
24 \\
18.9 \\
22.4 \\
11.3 \\
11.3 \\
21.2\end{array}$ \\
\hline
\end{tabular}

The average length of stay in the hospital of those patients with lobar pneumonia who recovered is between two weeks and one month, the larger number remaining about three weeks. It is impossible to go into the question of the complications in the present abstract. In many instances the connection between pneumococcus infection and the complications is not traceable, or at least was not followed out, and a discussion of the ordinary complications would take more time and space than can be expended in this connection. It may be mentioned, however, that the complications noted in the foregoing series included otitis media both with and without mastoiditis, phlebitis, empyema, myocarditis, acute corneal ulcer, decubitis, acute arthritis, all of the different forms of pleurisy, nephritis, meningitis, pulmonary abscess, bronchial asthma, gastro-enteritis, endocarditis and gangrene of the lung.

Donaldson Building.

Duration of Incubation of Syphilis.-One of the editors of the Annales de Dermatologie, G. Thibierge, publishes in the July issue a study of this subject. His data establish that in the vast majority of cases the incubation period ranges from fourteen to forty-two days, but that cases are on record in which the interval before symptoms developed was fifty, sixty and ninety days. $\mathrm{He}$ cites various authorities to show that the minimum seems to be ten days. In monkeys the range was ten to forty-nine. The average in man is between twenty-five and thirty days.

\section{INFECTIOUS DISEASES}

THEIR ADMINISTRATIVE CONTROL IN DIFFERENT CITIES OF THE UNITED STATES

S. DANA HUBBARD, M.D.

Chief, Division of Infectious Diseases, Bureau of Preventable Diseases, Department of Health

NEW YORK

The Department of Health of New York City, having made some changes in the rules and regulations regarding certain infectious diseases in order to be consistent with the teachings and opinions of members of the medical profession and the scientific knowledge of today, desired to ascertain the opinions of eminent sanitarians throughout the country regarding these matters.

A questionnaire was therefore sent to the health authorities of sixteen of the largest cities in the United States.

\section{QUESTIONNAIRE}

QUestron 1.-What procedure have you regarding persons exposed to scarlet fever and measles and who are immune by reason of having had this disease?

A. Exclusion from place of business when connected with the sale or handling of dairy or food products.

B. Exclusion of children from schools, it being assumed of course that the patient ill with either scarlet fever or measles is practically and efficiently quarantined.

Atlanta: A. Persons exposed to scarlet fever and measles must not handle food products offered for sale.

B. Children are excluded from school, but are allowed on the streets.

BALTIMORE: A. They must not remain on the premises in which there is a case of disease. If there is any doubt that 1his order will be carried out, the individual is prevented from attending to the food and dairy business.

B. If the children are removed to another house, then they can attend school.

Boston: A. Persons who have been exposed to scarlet fever and measles and who are protected by a previous attack of these diseases are not held under observation by this department unless engaged in the sale or handling of food or dairy products. If a case of scarlet fever occurs in the family of such a person, unless the patient is immediately removed to the hospital, persons in the family are forbidden to engage in the business of handling of food or dairy products. As regards measles, no action is taken. I am of the opinion that this disease cannot be carried.

B. Such children are not excluded from school.

Ciricago: A. In scarlet fever we exclude the person unless residence is changed during quarantine. In measles, no.

B. In scarlet fever, yes, unless change of address and furnish certificate of attack from physician. In measles, no, provided a certificate of immunity from physician is furnished.

Cincinnati: Quarantine for scarlet fever and diphtheria applies to all members of the family. We have an unwritten law that the breadwinner may continue his occupation, provided the patient is isolated and there is no contact.

A. If the parents are engaged in handling food or dairy products, patient must be removed to the hospital or the industry is closed.

B. In case of scarlet fever, diphtheria and measles, all children in the same family are excluded from school until the quarantine is raised by the health department. The history of a previous attack is not accepted as a sufficient reason that persons who have been exposed to scarlet fever, diphtheria or measles should return to school.

Cleveland: A. Persons exposed to measles and who are immune by reason of having had the disease are not excluded 